\title{
SOCIAL NORMS AND COMPLIANCE WITH ROAD TRAFFIC RULES IN URBAN AREAS: INITIAL IMPRESSIONS OF DRIVERS IN KAMPALA, UGANDA
}

\author{
FREDDIE F. MAWANGA* \\ JOSEPH M. NTAY|** \\ *ffmawanga@yahoo.co.uk,fmawanga@mubs.ac.ug \\ **ntayius@yahoo.com,jntayi@mubs.ac.ug \\ Faculty of Computing and Management Science \\ Makerere University Business School \\ P.O. Box 1337 \\ Kampala, Uganda
}

\begin{abstract}
Since 1998, the government of Uganda has formulated traffic rules for road drivers, set penalties for violation of these rules and deployed traffic personnel to enforce compliance. However, there is continued non-compliance with these rules, particularly among drivers of personal vehicles on Kampala roads. It is likely that the actions of these drivers are influenced by individual or social perceptions and pressures (social norms). These social norms include injunctive norms (influences from people that drivers respect), descriptive norms (influences from other drivers' behaviour) and perceived behaviour control (drivers exploiting available opportunities). The study explores the existence of these norms among drivers of personal vehicles and analyses the way the norms affect compliance with road traffic rules when moderated by road obstructions and control systems in Kampala, Uganda.
\end{abstract}

\section{INTRODUCTION}

\section{Background}

Compliance with road traffic rules by drivers is an ongoing challenge in Kampala, the capital city of Uganda. Traffic rules are said to be violated when drivers deliberately disobey formally prohibited or socially accepted codes of driving behaviour. The Uganda government has since 1998 formulated rules, prescribed heavy penalties and deployed enforcement traffic personnel on most Kampala roads (Traffic and Road Safety Act, 1998, No.15 of 1998, and Regulations, Kampala, Law Development Centre) as a way of ensuring compliance with road traffic rules by drivers. However, despite these efforts, there has been continued and increasing non-compliance with road traffic rules by drivers, including those driving personal vehicles.

Drivers on Kampala roads fail to respect traffic lights, cross restricted road lanes, talk on mobile phones while driving, and park at ungazetted points. Local reports in the Daily Monitor 
newspaper present similar problems, for example, that road accidents had increased since 2005 both on urban and upcountry roads due to non-compliance with traffic rules (August 6,2009 , p. 28). In the same daily, it was reported that four deaths had been recorded within the first two weeks of the opening the Northern Bypass Road in Kampala city and this was attributed to non-compliance with traffic rules among drivers (October 1, 2009, p. 3). This non-compliance can be attributed to social norms among the drivers (Björklund \& Åberg 2005). Social norms are standards of behaviour that are accepted within a particular group or society and consist of: perceived behavioural control, injunctive norms and descriptive norms. In driving, perceived behavioural control is a result of individuals exploiting existing opportunities on the roads; injunctive norms are due to pressures from people that drivers respect; and descriptive norms result from the way other drivers behave on the road (Lee, Geisner, Lewis, Neighbors \& Larimer, 2007).

Research indicates that social norms are a strong predictor of behaviour (Ajzen, 2006; Blanton, Köblitz \& McCaul, 2008); therefore, non-compliance with traffic rules by drivers may be attributed to social norms among drivers. There is need therefore, to understand social norms among drivers in order to improve compliance with road traffic rules.

\section{Purpose of the study}

This study focused on social norms of individuals driving personal vehicles on Kampala roads and it builds on Mbara's (2009) study on 'Driver Pretesting System in Zimbabwe: An analysis of impacts and perceptions' with the assertion that attitudes and acts such as speeding, non-compliance with traffic lights, driving on shoulders among other factors lead to many undesirable results on roads, most notably road accidents. We investigated the existence of perceived behaviour control, injunctive norms and descriptive norms among drivers on Kampala roads and the way these norms - apart from road obstructions and road control systems - predict driver compliance with road traffic rules in Kampala.

\section{LITERATURE REVIEW}

Social norms influence peoples' behaviour and according to Krupka and Weber's (2008) model, if $A=\left(a_{1}, a_{2}, \ldots . . a_{a k}\right)$ represents a set of $k$ social actions available to an individual, it is possible to assign a social norm, $N_{(a k)}$, a value $\left(N_{(a k)}>0\right)$ if the action supports the norm or a value $\left(N_{(a k)}<0\right)$ if the action deviates from the norm. In driving, these actions represent compliance and non-compliance with prescribed regulations or socially accepted codes of conduct.

Social norms are among the strongest predictors of behaviour (Ajzen, 2006; Blanton, et al., 2008). In driving, these norms are motivated by the benefits drivers foresee in making any 'sensible' action, 'the good thing' or 'what one ought to do'. These motivations are contextual since they depend on the individual, people around the actor and other external 
factors. For example, while driving, is it sensible to switch off the phone, put it on 'silent' or leave the volume on? Decisions by drivers on such issues may be in violation of set rules and this may be encouraged by the absence of rewards for compliance. That is why a study (Ajzen, 2006) found that fictional films demonstrating life-threatening use of motor vehicles are perceived as heroic or humorous although they violate well-formulated and -interpreted road traffic rules. The effect of social norms in driving is reconfirmed by Gaymard (2009) in the assertion that interventions to increase the level of compliance with road traffic rules have not been effective because formal rules and human conduct are studied from an individualist perspective rather than being a socially shared knowledge and understanding.

People respected by drivers influence their compliance with traffic rules (injunctive norms). Researchers like Björklund and Åberg (2005), Gopi and Ramayah (2007) and Lee et al. (2007) in a study on drink-driving, and Stasson and Fishbein (2006) in a study on the use of safety belts confirm this relationship. The respected people include peers, spouses, mentors, role-models and bosses. Injunctive norms are motivated by rewards associated with each action and that is why respected people 'who practise what they preach' have a stronger influence on the actors than the passive ones (Smith \& Louis, 2008). On basis of this literature, we hypothesise that: $\mathrm{H}_{1}$ : Perceived injunctive norms of people respected by drivers significantly relate to the drivers' level of compliance with road traffic rules.

Descriptive norms describe perceptions of what most group members actually do and this is a result of a conviction that 'if everyone is doing it, then it must be a sensible thing to do' (Rivis \& Sheeran, 2003). These actions may include speeding violations due to time pressures, impatience, annoyance and hostility towards other drivers (Walsh, White, Hyde \& Watson, 2008). These actions may lead to driving too closely behind a vehicle, violations of rights of way, risky overtaking and cutting in on other motorists. Evidence that drivers are affected by actions of other drivers on roads leads to the hypothesis that: $\mathrm{H}_{2}$ : Perceived descriptive norms significantly relate to compliance with road traffic rules by drivers.

Perceived behaviour control is the extent of performance of a specific behaviour by an individual according to their discretion (Rivis \& Sheeran, 2003; Gopi \& Ramayah, 2007; Walsh et al., 2008). Hence, perceived behaviour control (Kraft, Rise, Sutton \& Røysamb, 2005) can be internal (e.g. knowledge, skills, willpower) or external (e.g. time, cooperation of others). Such environments provide opportunities for actions that may be contrary to rules or socially accepted codes of conduct, like risky overtaking. Certain studies on driving revealed that perceived behaviour control was the main predictor of actual behaviour (Newnam, Watson \& Murray, 2004; Gopi \& Ramayah, 2007; Walsh et al., 2008), contradicting Conner, Smith and Mcmillan (2003) who found that injunctive norms were the main predictors. These contradictions emphasise the contextual and hierarchical correlations of these norms which are influenced by demographic factors like sex, age and peer group values (Gopi \& Ramayah, 
2007). This study uses a synergised approach of social norms in influencing compliance with road traffic rules thus, we hypothesise that: $\mathrm{H}_{3}$ : Perceived behaviour control significantly relates to compliance with road traffic rules.

$\mathrm{H}_{4}$ : Road obstructions and road control systems moderate the relationships between perceived descriptive norms, perceived injunctive norms, perceived behaviour control and compliance with road traffic rules.

$\mathrm{H}_{5}$ : The synergistic relationship between injunctive norms, descriptive norms and perceived behaviour control significantly and positively correlate with each other.

\section{RESEARCH STRATEGY}

\section{Discussion of the hypotheses}

Figure 1 shows the conceptual framework of the study based on the literature review and the contention of the researchers. The figure shows the independent, moderating and dependent variables of the study whose study variables are discussed.

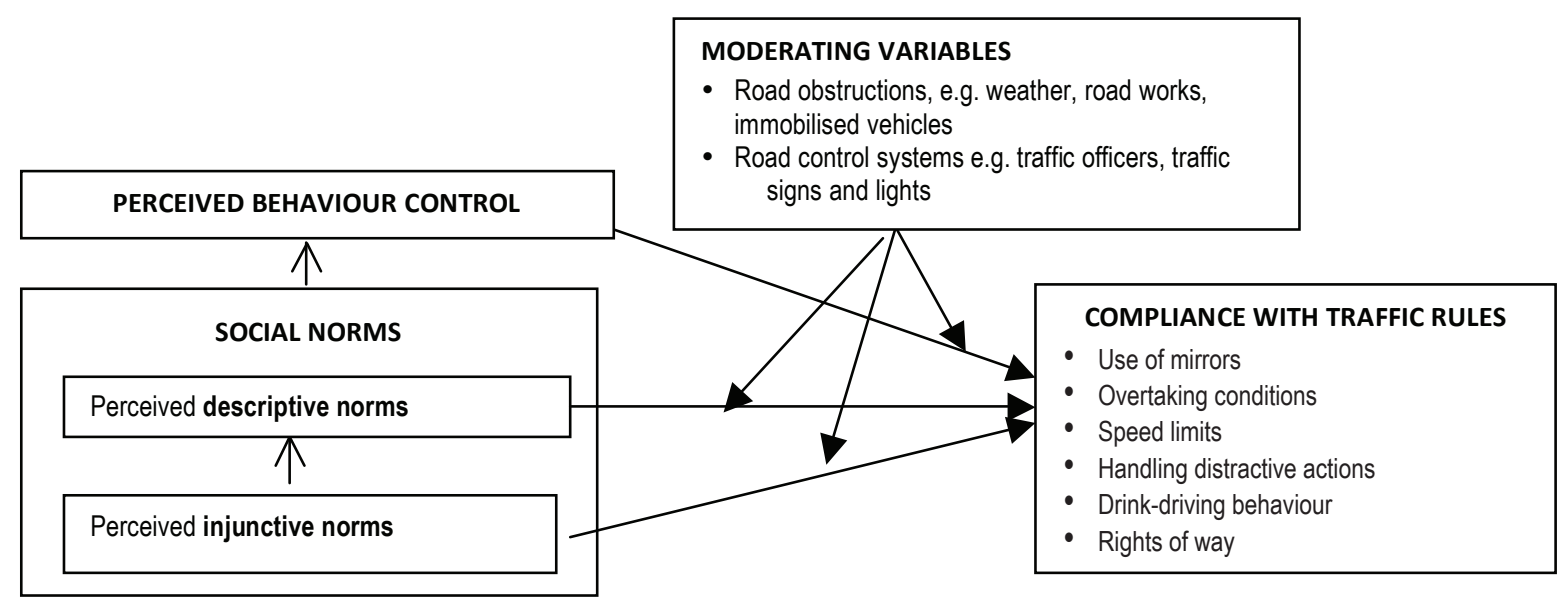

Figure 1: Conceptual framework

Source: Adapted from Adjzen (1991), Krupka \& Weber (2008)

and Evans \& Norman (1998)

The Figure 1 shows that the different aspects of social norms among drivers on roads are inter-related and they are also related to compliance with road traffic rules. When drivers are on the roads, their actions are moderated by road obstructions and road control systems. This framework confirms the hypotheses formulated.

\section{Research approach and participants}

The study was cross-sectional, descriptive and quantitative. It relied on primary data and was carried out in Kampala because of its continuous flow of road traffic, structured road network and road control systems. Focus was on drivers driving personal vehicles because they best fitted the social norms of the study. Using a population of 11000 personal vehicle 
drivers (Kumar \& Barrett, 2008; Uganda Road Fund, 2008), a random sample of 370 drivers at $95 \%$ confidence interval and margin error of $2.5 \%$ (Krejcie \& Morgan, 1970) was randomly selected to complete a self-administered questionnaire from which a useful response rate of $56 \%$ (208 respondents) was achieved. The demographic findings revealed that $80 \%$ of the respondents were male and $20 \%$ were female. Fifty-five per cent (55\%) of the population were married. Education analysis revealed that the majority $(71 \%)$ were university graduates, $15 \%$ had other tertiary qualifications, $9 \%$ had advanced-school education and $5 \%$ only had secondary education. Of all respondents, $48 \%$ were in the age range of $18-30$ years. The age ranges of $31-40$ years, $41-50$ years and $51-60$ years had $34 \%, 14 \%$ and $3 \%$ respondents respectively. Overall, 37\% of the respondents had driving experience of 2-5 years, while those with over 10 years, 6-10 years and at most one year of experience were 25\%, 20\% and $18 \%$ respectively. These distributions show that the respondents had varied social status, had acquired education to understand the self-reporting tools and had driven for a reasonable period to understand the road traffic rules and also to have knowledge of social norms related to driving.

\section{Measuring instruments}

Items of the study variables were measured on a five-point Likert scale. Items for injunctive norms included: 'People I respect are ... overtaking at any point'; 'People I respect are ... driving after drinking a little alcohol'; 'People I respect are ... driving closely behind other vehicles'. The item scales ranged from 1 (completely unacceptable) to 5 (completely acceptable) with 3 (neutral) as mid-value; their reliability coefficient was $\alpha=0.76$.

Items for descriptive norms were: 'Drivers race from one lane to another with no regard for other road users'; 'Drivers are impatient with other slow drivers'; 'Drivers drive closely to other vehicles to signal to them to drive faster'; 'Drivers race across traffic lights to beat cars beside them'. The items scales ranged from 1 (fully disagree) to 5 (fully agree) with 3 (not sure) as mid-value, (Ajzen, 2006; Hemenway, Vriniotis \& Miller, 2006); their reliability coefficient was $\alpha=0.65$.

Items for perceived behaviour control included: 'I ignore traffic rules to keep traffic going'; 'I take risks to show that I am a good driver'; 'I drive on Kampala roads without any problems' on a scale ranging from 1 (never) to 5 (almost all times) and 3 (not sure) as mid-value (Ajzen, 2006; Conner et al., 2003); their reliability coefficient was $\alpha=0.70$.

Items for compliance with traffic rules were: 'I try to overtake someone I had not noticed turning'; 'I nearly hit another car while entering a main road'; 'I do not see STOP or GIVE WAY signs'; 'I fail to check in my mirror when changing lanes'; 'I drive safely while talking on the phone'; 'I drive in the middle of road lanes and force other drivers to other lanes', measured on a scale ranging from 1 (never) to 5 (almost all times) with 3 (not sure) as midvalue (Hemenway et al., 2006); their reliability coefficient was $\alpha=0.82$. 
Items for road obstructions included: 'I see vehicles that have broken down on Kampala roads'; 'I see road construction works on Kampala roads'; 'There are poor drainage systems on Kampala roads' measured on a scale ranging from 1 (never) to 5 (almost all times) with 3 (not sure) as mid-value (Hemenway et al., 2006); their reliability coefficient was $\alpha=0.54$.

Road control systems items included: 'There are enough walkways for pedestrians on Kampala roads'; 'Behaviour of road traffic officers on Kampala roads is OK'; 'There are enough functional traffic control lights and signs on Kampala roads'. They were measured on scale ranging from 1 (never) to 5 (almost all times) with 3 (not sure) as mid-value (Hemenway et al., 2006); their reliability coefficient was $\alpha=0.49$.

\section{Procedure}

Research assistants were allocated questionnaires that were randomly distributed in offices, recreational areas and washing bays within Kampala city.

\section{Statistical analysis}

Data was analysed to generate descriptive statistics, bivariate Pearson correlation coefficients, and a hierarchical regression analysis as shown in Table I and Table II. The hierarchical regression involves introducing independent variables in the model cumulatively and analysing the generated output at each stage. Gender and marital status are categorical values. Male drivers and married drivers were in the majority as respondents according to gender and marital status respectively. The majority respondents were each assigned a dummy value 1 and the alternatives were assigned a dummy value 0 to conform with the requirements for the analysis. The Variance Inflation Factor (VIF) measures the impact of collinearity among variables in a regression and its square root is the factor; its standard error in the model is compared to its corresponding value when used alone in the model; and they were all within the recommended range (VIF $<4)$, showing non-collinearity.

Table I: Descriptive statistics and Pearson inter-correlations

\begin{tabular}{|c|c|c|c|c|c|c|c|c|c|c|c|c|c|}
\hline & Mean & S.D. & 1 & 2 & 3 & 4 & 5 & 6 & 7 & 8 & 9 & 10 & 11 \\
\hline Male drivers (1) & 0.80 & 0.402 & 1 & & & & & & & & & & \\
\hline Married drivers (2) & 0.55 & 0.498 & $.174^{\star \star}$ & 1 & & & & & & & & & \\
\hline Education level (3) & 3.53 & 0.846 & $-.166^{\star *}$ & $-.248^{\star \star}$ & 1 & & & & & & & & \\
\hline Age range (4) & 1.72 & 0.818 & $.210 \star \star$ & $.535^{\star \star}$ & $-.170 \star \star$ & 1 & & & & & & & \\
\hline Driving experience (5) & 2.51 & 1.053 & $.406^{\star \star}$ & $.464^{\star \star}$ & $-.263^{\star \star}$ & $.606^{\star \star}$ & 1 & & & & & & \\
\hline $\begin{array}{l}\text { Perceived behaviour } \\
\text { control (6) }\end{array}$ & 4.01 & 1.045 & -.010 & .000 & -.084 & -.055 & -.033 & 1 & & & & & \\
\hline Injunctive norms (7) & 4.20 & 0.924 & .037 & -.001 & .044 & -.034 & .060 & $.318^{\star \star}$ & 1 & & & & \\
\hline Descriptive norms (8) & 4.81 & 0.736 & .017 & $-.188^{\star \star}$ & .062 & $-.181 \star \star$ & .025 & .381 *夫 & $.261^{\star \star}$ & 1 & & & \\
\hline Road obstructions (9) & 4.89 & 0.784 & -.105 & -.081 & .101 & -.041 & -.055 & .052 & .060 & -.026 & 1 & & \\
\hline $\begin{array}{l}\text { Road control } \\
\text { systems }(10)\end{array}$ & 3.03 & 0.831 & $.143^{\star}$ & .035 & -.065 & .046 & $.119^{\star}$ & .039 & $.194^{\star \star}$ & .038 & $.167^{\star \star}$ & 1 & \\
\hline $\begin{array}{l}\text { Compliance with } \\
\text { road traffic rules (11) }\end{array}$ & 3.52 & 0.570 & -.076 & $-.126^{\star}$ & .033 & -.093 & .027 & $.355^{\star \star}$ & $.349 * \star$ & $.545^{\star \star}$ & -.066 & .000 & 1 \\
\hline
\end{tabular}


Table 2: Hierarchical Regression

(Compliance with road traffic rules as dependent variable)

\begin{tabular}{|c|c|c|c|c|c|c|c|}
\hline Variable & Model 1 & Model 2 & Model 3 & Model 4 & Model 5 & Model 6 & Collinearity \\
\hline & & & & & & & VIF \\
\hline (Constant) & $-1.488^{\star \star}$ & $-1.384^{\star \star}$ & $-1.228^{\star \star}$ & $-.961 * \star$ & $-.980 \star \star$ & $-.974^{\star \star}$ & \\
\hline Male & -.090 & & & & & & 1.223 \\
\hline Partnered & -.118 & & & & & & 1.532 \\
\hline Education & .014 & & & & & & 1.108 \\
\hline Age & -.146 & & & & & & 1.890 \\
\hline Driving experience & $.208^{\star}$ & $.205^{\star}$ & .156 & .021 & .022 & .024 & 2.113 \\
\hline Perceived behaviour control & & $.335^{\star \star}$ & .245 & .090 & .095 & .092 & 1.013 \\
\hline Injunctive norms & & & $.270 * \star$ & $.222^{\star \star}$ & $.228^{\star \star}$ & $.238^{\star \star}$ & 1.151 \\
\hline Descriptive norms & & & & $.454^{\star \star}$ & $.447^{\star \star}$ & $.448^{\star \star}$ & 1.339 \\
\hline Road obstructions & & & & & -.095 & -.084 & 1.023 \\
\hline Road control systems & & & & & & -.052 & 1.117 \\
\hline $\mathrm{R}$ & .189 & .383 & .458 & .603 & .610 & .612 & \\
\hline R square & .036 & .146 & .210 & .364 & .373 & .375 & \\
\hline Adjusted R Square & .010 & .118 & .180 & .336 & .341 & .340 & \\
\hline R Square change & .036 & .111 & .064 & .154 & .009 & .002 & \\
\hline F - Statistics & 1.363 & 5.229 & 6.907 & 12.936 & 11.878 & 10.740 & \\
\hline Sig. & .500 & .000 & .000 & .000 & .113 & .408 & \\
\hline \multicolumn{8}{|c|}{$N=208, \quad * \star \quad$ Regression is significant at the 0.01 level, } \\
\hline
\end{tabular}

\section{RESULTS AND DISCUSSION}

\section{Injunctive norms and compliance with road traffic rules}

There was hardly any compliance with road traffic rules (mean $=3.52$, S.D. $=0.57$ ) because, overall, drivers' responses showed that they were not sure of their actions on the roads in relation to set rules. Respondents showed that most people they respected engaged in actions that deviated from traffic rules (mean $=4.20$, S.D. $=1.045)$, for instance, talking on the phone while driving and overtaking at any point. The injunctive norms were positively and significantly related to compliance with traffic rules $(r=0.349 * *, p<0.01)$, supporting $\mathrm{H}_{1}$ that perceived injunctive norms of people respected by drivers significantly affect the drivers' level of compliance with road traffic rules. It is likely that time constraints and pressure from peers, bosses, mentors and spouses to demonstrate driving skills contribute to these norms. This is consistent with Gueguen and Pichot (2001) who found that pedestrians were more likely to disobey signals at a crosswalk when following an offender perceived to be of high status.

\section{Descriptive norms and compliance with road traffic rules}

The respondents perceived other drivers' actions on roads as aggressive, i.e. showing no concern for other road users as indicated by descriptive norms (mean $=4.81$, S.D. $=0.736$ ). Descriptive norms were positively and significantly related to compliance with traffic rules 
( $r=0.545^{\star \star}, \mathrm{p}<0.01$ ) supporting $\mathrm{H}_{2}$ that perceived descriptive norms significantly relate to compliance with road traffic rules by drivers.

\section{Perceived behaviour control and compliance with road traffic rules}

The respondents indicated that drivers are confident on the roads ( $m e a n=4.01$, S.D. $=0.924$ ), and thus exploit any available opportunities to keep moving even when the opportunities conflict with set rules and socially accepted codes of driving. Opportunities included taking risks to show off driving skills. The perceived behaviour control was positively and significantly related to compliance with the traffic rules $\left(r=0.355^{\star *}, p<0.01\right)$, which supports $H_{3}$ that perceived behavioural control significantly relates to compliance with road traffic rules. Ajzen (2006) asserts that perceived behaviour control can serve as a proxy for actual control and contribute to the predictive value of the variable of the behaviour in question.

\section{Synergistic correlations}

The study revealed that bivariate correlations between the independent variables were positive and significant. The correlation for perceived behaviour control and descriptive norms was $\left(r=0.381^{* *}, p<0.01\right)$; perceived behaviour control and injunctive norms was $\left(r=0.318^{\star *}, p<0.01\right)$; and descriptive norms and injunctive norms was $\left(r=0.261^{\star \star}\right.$, $\mathrm{p}<0.01$ ), supporting $\mathrm{H}_{5}$ that the synergistic relationship between injunctive norms, descriptive norms and perceived behaviour control significantly and positively correlate to each other.

The perceived control behaviour-descriptive norm correlation is likely to be a result of drivers learning to drive from other 'experienced drivers' rather than driving schools and these become their role models. Injunctive pressures and perceived behaviour control are correlated because it is likely that the overt and covert injunctive rewards make drivers voluntarily or involuntarily demonstrate control behaviours. Furthermore, the correlation between descriptive and injunctive norms confirms a likelihood that the respected people exert pressure on drivers after observing actions of other drivers, particularly when there is a need to keep traffic flowing.

Road obstructions (mean $=1.89, \mathrm{~S} . \mathrm{D}=0.784$ ) hardly exist. That is why it had no significant correlation with all model constructs and with road traffic rules $(r=-0.066)$. The nonsignificant, though negative correlation with descriptive norms $(r=-0.026)$ is rather interesting and contrary to what would have been expected but this could be that when other drivers know that the road is clear, they tend to drive more recklessly. The respondents indicated that road control systems (mean $=3.03$, S.D. $=0.831$ ) like walkways, traffic signals and traffic personnel generally existed though with no link to compliance with traffic rules $(r=0.00)$. This lack of correlation may be attributed to the ignorance of drivers (because they never went to formal driving schools) or an attitudinal problem, thus highlighting a very serious finding in respect of compliance with traffic rules. Interestingly, road control 
systems were significantly and positively related to injunctive norms $\left(r=0.194^{\star *}, p<0.01\right)$ and to road obstructions $\left(r=0.167^{\star *}, p<0.01\right)$. It is likely that the respected people always look out for control systems to alert drivers intending to violate traffic rules. Furthermore, effective road control systems like traffic personnel would significantly reduce traffic road obstructions by redirecting traffic. These findings support $\mathrm{H}_{4}$ that road obstructions and road control systems moderate the relationship between perceived descriptive norms, perceived injunctive norms, perceived behavioural control and compliance with road traffic rules.

\section{Model analysis}

Model 1 has controlled demographic variables (sex, marital status, education, age and driving experience) and reveals that these variables other than driving experience, never predict compliance with traffic rules (adjusted $\mathrm{R}$ square $=1.0 \%, \mathrm{~F}$ statistics $=1.363$ ). The small predictive value of the variable is by the constant $\left(\beta=-1.488^{\star *}, p<0.01\right)$ and driving experience $\left(\beta=0.208^{*}\right.$, $\left.p<0.5\right)$.

In model 2, when perceived behaviour control is introduced it becomes a significant predictor of compliance with traffic rules $\left(\beta=0.335^{\star *}, \mathrm{p}<0.01\right.$ ); (adjusted $\mathrm{R}$ square $=$ $11.8 \%, F$ statistics $=5.229$ ). Its presence reduces the predictive value of the variable by the constant and driving experience. This confirms the influence of exploiting opportunities by drivers as they gain competence to overcome internal and external constraints on roads. Furthermore, perceived control behaviour and driving experience are significant because repeated actions lead to skills improvement and better understanding of the road network, thus improving the behaviour control.

In model 3, when injunctive norms are introduced they are significant predictors of compliance with traffic rules, $(\beta=0.270 * *, p<0.01)$; (adjusted $R$ square $=18.0 \%$, F statistics $=6.907$ ). It is interesting that driving experience and perceived behaviour control become non-significant in this model, thus showing that existence of respected people suppresses all prior predictors. The respected people are most likely to assist drivers by monitoring of road control systems and other road activities.

In model 4 , introducing descriptive norms significantly predicts compliance with traffic rules, $\left(\beta=0.454^{\star *}, p<0.01\right.$ ); (adjusted $\mathrm{R}$ square $=33.6 \%, \mathrm{~F}$ statistics $\left.=12.936\right)$. The predictive value of the variable by the constant and injunctive norms decrease further, showing the complementary effect of each of these predictors. The model reveals that actual compliance with traffic rules highly depends on other drivers on the road who are involved in aggressive driving and speeding. This is consistent with Feldman and Harel (2007), who found that social norms of non-compliance had a much greater effect than social norms of compliance in any society. This indicates a greater need for examination of social norms in compliance with traffic rules.

Models 2, 3 and 4 prove that perceived behaviour control, injunctive norms and descriptive norms predict compliance with road traffic rules when introduced in that order, reconfirming 
$\mathrm{H}_{5}$ that the synergistic relationship between injunctive norms, descriptive norms and perceived behavioural control significantly and positively correlate with one another and compliance with road rules.

While there is an increase in the overall predictive value of the variable according to model 5 (adjusted R square $=34.1 \%, F$ statistics $=11.878$ ), it decreased in model 6 (adjusted R square $=34.0 \%$, $\mathrm{F}$ statistics $=10.740 \%$, thus showing the complementary role the systems have on ensuring compliance with road traffic rules.

\section{CONCLUSION AND RECOMMENDATIONS}

The government of Uganda has consistently reviewed road traffic rules, deployed traffic personnel and invested in road control systems to enforce compliance. However, this study revealed that drivers of personal vehicles do not comply with road traffic rules due to social norms (perceived descriptive norms, perceived injunctive norms and perceived control behaviour in decreasing order respectively). The government of Uganda has done little to understand these social norms. It was also revealed that road obstructions and road control systems hardly relate to compliance with road traffic rules. While these findings are from Uganda, this gives an insight into a need for a worldwide social-norm approach in training drivers to make compliance with road traffic rules more efficient and effective.

Government should therefore introduce a driving training curriculum with involvement of the transport licensing board, traffic personnel, traffic associations like the Driving Standards Agency, prominent individuals, and local authorities. The public should be sensitised by the transport licensing board and other transport associations through workshops, print and electronic media on the critical value social norms play in using roads; refresher courses for drivers should also be spearheaded by the same organs. Furthermore, Face Technologies, the agency responsible for issuing road driving permits, should make provisions on the permits to keep records of traffic offences made by drivers for effective monitoring, control and evaluation of non-compliance with road traffic rules.

\section{Limitations}

Measurement of social norms and compliance with traffic rules were done through selfassessment tools that may have had biased responses by respondents if they focused on their friends or people with closely related behaviour.

\section{Areas for further research}

An extension of this study should cover strategies for using a social norm approach in improving compliance with road traffic rules, the way driving behaviours relate to urban road traffic congestion and a comparative study on whether there is a significant difference in social norms and compliance with road traffic rules according to driver demographic factors. 


\section{REFERENCES}

Ajzen, I. (1991). The theory of planned behavior. Organizational Behavior and Human Decision Processes, 50, 179-211.

Ajzen, I. 2006. Constructing a TpB questionnaire: Conceptual and methodological considerations: brief description of the theory of planned behavior. Available http://www. people.umass.edu/aizen/pdf/tpb.measurement.pdf (accessed 24 July 2009).

Björklund, G. \& Åberg, L. 2005. Driver behaviour in intersections: Formal and informal traffic rules. Transportation research Part F. Traffic Psychology and Behaviour, 8(3): 239-53.

Blanton, H., Köblitz, A. \& McCaul, K. 2008. Misperceptions about norm misperceptions: Descriptive, injunctive, and affective 'social norming' efforts to change health behaviors. Journal of Social and Personality Psychology Compass, 2(3): 1379-99.

Conner, M., Smith, N. \& Mcmillan, B. 2003. Examining normative pressure in the theory of planned behaviour: impact of gender and passengers on intentions to break the speed limit. Current Psychology: Developmental, Learning, Personality, 22(3): 252-63.

Evans, D. \& Norman, P. 1998. Understanding pedestrians' road crossing decisions: An application of the theory of planned behaviour. Health Education Research, Theory \& Practice, 13(4) 481-89.

Feldman, Y. \& Harel, A. 2007. Social norms, self-interest and ambiguity of legal norms: An experimental analysis of the rule $v$. standard dilemma, working paper series. Social Science Research Network. Available: http://ssrn.com/abstract=989216 (accessed 23 September 2009).

Gaymard, S. 2009. Norms in social representations: Two studies with French young drivers. The European Journal of Psychology Applied To Legal Context, 1(2): 165-81.

Gopi, M. \& Ramayah, T. 2007. Applicability of theory of planned behavior in predicting intention to trade online: Some evidence from a developing country. International Journal of Emerging Markets, 2(4): 348-60.

Gueguen, N. \& Pichot, N. 2001. The influence of status on pedestrians' failure to observe a road-safety rule. Journal of Social Psychology, 141(3): 413-15. 
Hemenway, D., Vriniotis, M. \& Miller, M. 2006. Is an armed society a polite society? Guns and road rage. Journal of Accident Analysis \& Prevention 38(4): 687-95.

Kraft, P., Rise, J., Sutton, S. \& Røysamb, E. 2005. Perceived difficulty in the theory of planned behaviour: Perceived behavioural control or affective attitude? British Journal of Social Psychology, 44: 479-96.

Krejcie \& Morgan 1970. Determining sample size for research. Activities, Educational and Psychological Measurement, 30: 607-10.

Krupka, E. \& Weber, R. 2008. Identifying social norms using coordination games: Why does dictator game sharing vary? Discussion paper No. 386. Bonn: The Institute for the Study of Labor (IZA).

Kumar, A. \& Barrett, F. 2008. Stuck in traffic: Urban transport in Africa. Africa Infrastructure Country Diagnostic. World Bank and the SSATP.

Lee, C., Geisner, I., Lewis, M., Neighbors, C. \& Larimer, M. 2007. Social motives and the interaction between descriptive and injunctive norms in college student drinking. Journal of Studies on Alcohol and Drugs, 68(5): 714-21.

Mbara, T. 2009. Driver pretesting system in Zimbabwe: An analysis of impacts and perceptions. Journal of Transport and Supply Chain Management, 3: 38-58.

Newnam, S., Watson, B. \& Murray, W. 2004. Factors predicting intentions to speed in a work and personal vehicle. Transportation research Part F. Traffic Psychology and Behaviour, 7(45): 287-300.

Rivis, A. \& Sheeran, P. 2003. Descriptive norms as an additional predictor in the theory of planned behaviour: A meta-analysis. Current Psychology: Developmental, Learning, Personality, Social, 22(3): 218-33.

Smith, J. \& Louis, W. 2008. Do as we say and as we do: The interplay of descriptive and injunctive group norms in the attitude-behaviour relationship. British Journal of Social Psychology, 47: 647-66.

Stasson, M. \& Fishbein, M. 2006. The relation between perceived risk and preventive action: A within-subject analysis of perceived driving risk and intentions to wear seatbelts. Journal of Applied Social Psychology, 20(19): 1541-57. 
Uganda Road Fund. 2008. The transport sector. Road Sector Development Programme (RSDP), Ministry of Finance, Planning and Economic Development. Kampala.

Uganda Government (1998), Traffic and Road Safety Act, 1998, No.15 of 1998, and Regulations, Kampala, Law Development Centre.

Walsh, S., White, K., Hyde, M. \& Watson, B. 2008. Dialling and driving: Factors influencing intentions to use a mobile phone while driving. Journal of Accident Analysis and Prevention, 40(6): 1893-1900. 